\title{
Estudio y análisis presuntivo de la fertilidad microbiana del suelo de un cultivo de maíz (Zea mays) en Pamplona, Norte de Santander
}

\section{Study and presumptive characterization of soil from a corn crop (Zea mays) in Pamplona, Norte de Santander}

\begin{abstract}
Rojas C. Liliana1.; Cajiao P. Angela'.; Rivera V. Kevin².
1 Facultad de Ciencias Básicas, Universidad de Pamplona. Grupo de Investigación en Microbiología y Biotecnología-GIMBIO-. olrojas@unipamplona.edu.co.

2 Departamento de Microbiología, Facultad de Ciencias Básicas, Universidad de Pamplona. Semillero de Investigación en Microbiología y Biotecnología -SIMBIO-. Kevin.rivera@unipamplona.edu.co
\end{abstract}

\section{Resumen}

En el presente estudio se analizó el suelo de un cultivo de maíz de la ciudad de Pamplona, Norte de Santander. El objetivo de este radicó en la recuperación y análisis de las funciones que cumplen los microorganismos en los diferentes ciclos biogeoquímicos (amonificantes, nitrificantes, desnitrificantes, celulolíticos, amilolíticos y hongos antagonistas) del suelo de un cultivo de maíz localizado a $07^{\circ} 23^{\prime} 20.6^{\prime \prime}$ norte y $72^{\circ} 38.59^{\prime} 0^{\prime \prime}$ oeste y altitud de 2200 msnm. Se realizaron análisis físicos y químicos convencionales de: $\mathrm{pH}$, humedad, densidad, capacidad de retención de agua y colorimétricos para poder establecer las condiciones propias del suelo y establecer como en función de esto se desarrollan las diferentes poblaciones microbianas $y$ así proceder a realizar el análisis microbiológico mediante metodologías tradicionales de aislamiento, en el que se estudiaron microorganismos que intervienen en los ciclos biogeoquímicos del nitrógeno (amonificantes, nitrificantes y desnitrificantes), en el ciclo del carbono (celulíticos y amilolíticos) y posibles hongos con capacidad antagónica. Se obtuvo el recuento de una población total de 48 y 37 millones de bacterias y hongos respectivamente, donde se estimó que el $28,7 \%$ intervienen en el ciclo del nitrógeno, el $15,5 \%$ en el ciclo del carbono, aproximadamente un $55.8 \%$ de microorganismos no intervienen en ningún proceso estudiado $\mathrm{y}$ de 10 hongos con posible actividad antagónica: se obtuvo uno del género Penicillium spp. con capacidad de inhibir bacterias como $E$. coli y $S$. 
Palabras clave: amonificantes, antibióticos, ciclos biogeoquímicos, nitrificantes.

\section{Abstract}

In the current study at the city of Pamplona, Norte de Santander a corn harvest's soil was analyzed. The purpose of present study resided in the recovery and analysis of the functions that the microorganisms fulfil in the different biochemical cycles (ammonificants, nitrificants, desnitrificants, celulotics, amiolitics and antagonist mushrooms) from the corn harvest's soil, , located at $07^{\circ} 23$ '20.6' 'north and $72^{\circ} 38.59^{\prime} 0$ " west and altitude of 2200 meters above sea level. Physics and chemist conventional analysis were carried out such as, PH, humidity, density, water's retention capacity and colorimetrics in order to establish the original soil's conditions and also, how according to this the different microbial populations develop their self-aiming at making the microbiological analysis by means of isolation traditional methodologies in which the microorganisms were studied that intervene in the nitrogen's biogeochemical cycles (ammonificants, nitrificants and desnitrificants), in the carbon's cycle (celulotics and amiolitics) and possible mushrooms with antagonistic capacity. As a result, a recount of a complete population of 48 and 37 million of bacteria and mushrooms respectively was obtained, where it was estimated that the $28,7 \%$ intervene in the nitrogen's cycle, the $15,5 \%$ in the carbon's cycle, approximately a $55,8 \%$ of microorganisms do not take part in any studied process and from a ten-molds sample with possible antagonistic activity: one Penicillium spp. gender with the capacity of inhibit bacteria such as $E$. coli and $S$. aureus was obtained.

Key words: ammonificants, antibiotics, biogeochemical cycles, nitrificants. 
1.- Introducción

El suelo es un medio heterogéneo y complejo, constituido por minerales y otros materiales inorgánicos (óxidos de hierro, aluminio y silicio) de la corteza terrestre, por organismos vivos y por los restos orgánicos de los organismos muertos. Algunos residuos orgánicos, como la lignina, el componente estable de las plantas leñosas, son muy persistentes ya que resisten la descomposición microbiana; estos materiales se acumulan y constituyen la fracción orgánica del suelo denominada humus, la cual da al mismo el característico color marrón o negro (Ingraham \& Ingraham, 1998).

Gran parte de la productividad de los cultivos está determinada por la fertilidad del suelo. Esa fertilidad puede ser evaluada con base en sus características físicas (densidad, estructura, porosidad, etc.), químicas (actividad de las arcillas, potenciales de óxido-reducción, materia orgánica, etc.) y biológicas (microorganismos que conforman la microbiota y micro fauna, además de la meso y macro fauna). Las interacciones que se derivan de estas tres características producen cambios significativos en los ciclos biogeoquímicos del suelo y en la disponibilidad de nutrientes para las plantas.

La microbiota del suelo tiene una gran variedad de microorganismos; formada por una mezcla microscópica
05

de millones de bacterias, actinomicetos, hongos, protozoos, etc., por cada gramo de suelo (Rodríguez, 2002).

La sostenibilidad de los agroecosistemas se fundamenta en las regulaciones biológicas que se establecen en ellos, de tal forma que la diversidad existente permite que los organismos que la conforman sean regulados por la presencia de antagonistas. Existen muchos microorganismos del suelo reportados como productores de metabolitos biológicamente activos, dentro de estos se encuentran los hongos, bacterias y Actinomicetos, cuyo metabolismo y capacidad de producción, ha sido apenas investigada, por lo que se tiene como prioridad básica la búsqueda de grupos de microorganismos a partir de ambientes poco comunes como es el suelo (Valencia, 2001).

En el presente estudio se busca analizar las condiciones del suelo partiendo de las propiedades fisicoquímicas de este para poder estimar y estudiar las actividades llevadas a cabo por microorganismos que intervienen en los diferentes ciclos biogeoquímicos con el fin de conocer qué poblaciones microbianas están presentes y su actividad metabólica.

\section{Metodología}


A partir de una muestra de suelo de un cultivo de maíz de aproximadamente $16 \mathrm{~m}^{2}$, localizado a $07^{\circ} 23^{\prime} 20.6^{\prime \prime}$ norte y $72^{\circ} 38.59^{\prime} 0^{\prime \prime}$ oeste y altitud de 2200 msnm. Se tomó una muestra a $20 \mathrm{~cm}$ de profundidad en un área de $10 \mathrm{~cm}^{2}$, se realizó un cuarteo donde 2/4 partes se destinaron para hacer pruebas microbiológicas y las 2/4 partes restantes se destinaron para la pruebas de textura (tamizado) y fisicoquímicas como muestra la Tabla 1.

\section{Determinación de características fisicoquímicas}

Los métodos aplicados a las diferentes determinaciones fisicoquímicas del suelo se presentan en la Tabla 1.

Tabla 1. Pruebas fisicoquímicas

\begin{tabular}{|c|c|}
\hline Parámetro & Método \\
\hline $\boldsymbol{p H}$ & $\begin{array}{c}\text { Potenciómetro en } \\
\text { solución acida, } \\
\text { básica y alcalina) }\end{array}$ \\
\hline Humedad & $\begin{array}{c}\text { Balanza (PRECISA } \\
\text { XM 60) }\end{array}$ \\
\hline Densidad & Técnica de la probeta \\
\hline CRA & Método de campo \\
\hline Color & Tabla de Munsell. \\
\hline Granulometría & Triángulo de texturas. \\
\hline
\end{tabular}

Aislamiento y evaluación de Características microbiológicas.

Se tomaron 11 gramos de suelo, se diluyeron en $99 \mathrm{ml}$ de solución salina al $80 \%(\mathrm{p} / \mathrm{v})$ llevándose hasta la dilución $10^{-7}$. Se siembran en PDA y
06

SPC para realizar conteo total de microorganismos $y$ en medios funcionales como se presenta en la Tabla 2.

Para la determinación de antagonismo se sembró en Agar PDA y se incubó 74 horas a $25^{\circ} \mathrm{C}$, seguidamente en forma masiva se sembraron bacterias como E. coli ATCC 25922 y S. aureus ATCC 25923 y se incubó por 18 horas a $37^{\circ} \mathrm{C}$.

En la Tabla 2, se muestran las metodologías utilizadas para las diferentes determinaciones microbiológicas.

Tabla 2. Análisis microbiológicos

\begin{tabular}{|c|l|}
\hline Prueba & \multicolumn{2}{|c|}{ Método } \\
\hline Amonificantes & \multicolumn{2}{|l|}{ Siembra en superficie } \\
en agar urea
\end{tabular}

\section{Resultados}

\section{Características fisicoquímicas}

Las características fisicoquímicas del suelo, en diferentes grados, pueden afectar la actividad y dinámica de las poblaciones microbianas; al interaccionar la muestra con las diferentes soluciones se encontró que este suelo presenta liberación de ion hidrogenión; con base en esto se 
07

establece una capacidad baja de intercambio catiónico por la alta concentración de protones $(\mathrm{H}+)$ ocupando los espacios en los agregados que podrían ocupar cationes de Calcio, Magnesio y Potasio. En la Tabla 3 se muestran las características fisicoquímicas del suelo analizado, estas cobran importancia en el conocimiento del suelo debido a que influyen en el crecimiento de las plantas, en el manejo del suelo y por ende en su producción. Estas características determinan la rigidez y fuerza de sostenimiento, la facilidad para la penetración de las raíces, la capacidad de almacenamiento de agua y la retención de nutrientes.

Tabla 3. Resultado de pruebas fisicoquímicas

\begin{tabular}{|c|c|}
\hline Parámetro & Resultado \\
\hline$p H$ & 5,54 \\
\hline \% Humedad & 18,02 \\
\hline \multirow{2}{*}{ Densidad $\left(\mathrm{g} / \mathrm{cm}^{3}\right)$} & Real: 1,86 \\
\hline & Aparente: 1,47 \\
\hline \multirow{2}{*}{$C R A(m l)$} & Seca: 1,3 \\
\hline & Humeda:0,7 \\
\hline \multirow{2}{*}{ Color } & $\begin{array}{l}\text { Seco: Polo de color } \\
\text { marrón (10YR 6/3) }\end{array}$ \\
\hline & $\begin{array}{c}\text { Húmedo: Gris muy oscuro } \\
(7.5 Y R \text { 3/1) }\end{array}$ \\
\hline Granulometría & suelo franco arcilloso \\
\hline
\end{tabular}

El pH que presenta el suelo $(5,54)$, lo clasifica como fuertemente ácido, indica que su fertilidad será menor y aumenta la posibilidad de presentar elementos tóxicos, además indica intensa alteración de minerales y la estructura se vuelve inestable.
En estudios realizados por Pérez, (2008) en suelos de cultivo de Tabaco y en suelo de cultivo de maíz en Bogotá, encontraron que los pHs entre 4,0 -7,0 presentaron buenos rendimientos ya que el fósforo factor clave para la formación de raíces se encuentra disponible a estos valores de $\mathrm{pHs}$ para las plantas.

El porcentaje de humedad permite establecer que se tiene un suelo húmedo atendiendo a la retención de agua que hacen las arcillas y la materia orgánica (Salamanca \& Sadeghian., 2005). Siendo uno de los parámetros que más influye en cuanto a la productividad e incluso en el uso de fertilizantes y producción de maíz por sus características (Cruz, 2013).

Los valores de densidad aparente sustentan que se trata de un suelo franco de tipo arenoso-arcilloso valores bastante relacionados con la humedad con un valor de $18,02 \%$. La densidad aparente refleja la masa de una unidad de volumen de suelo seco, con el valor obtenido se puede establecer equivalencias entre las relaciones masa/masa (forma habitual de medir los parámetros del suelo) y masa/superficie (utilizadas en la aplicación de fertilizantes o para corregir deficiencias de acidez).

La densidad real $(1,86)$, constituye la densidad de la fase sólida del suelo, es un valor muy permanente pues la mayor parte de los minerales arcillosos 
08

presentan una densidad que está alrededor de 2,65 gramos por $\mathrm{cm}^{3}$.

EI CRA representa la cantidad de agua que necesita la planta para alcanzar su saturación total y es un indicador excelente del balance hídrico de la planta, la capacidad de retención de agua en muestra seca y húmeda nos muestra que el agua micro capilar presente en la muestra es de 0,6 . Mantienen una humedad de $60 \%$ aproximadamente.

El color gris que presenta el suelo indica que menos oxígeno tiene y más perjudicial es para las plantas.

Siguiendo el método clásico promediando los porcentajes obtenidos de arena, limo y arcilla: $40 \%, 30 \%$ y $30 \%$, respectivamente y revisando en el triángulo de textura se encontró que se trata de un suelo franco arcilloso.

La textura de los suelos genera que las condiciones de porosidad, formación de agregados, endurecimiento, aireación, capacidad de retención de agua, etc., sean diferentes en cada tipo de suelo, condicionando las poblaciones microbianas (en suelos con mayor cantidad de arcilla se encuentran niveles más altos de biomasa microbiana) y las condiciones del suelo para su uso a nivel agrícola se requieren texturas más gruesas con mayor aireación pero que tengan buenos niveles de retención de agua (Lacasta \& col, 2006) y por su tonalidad se determina la presencia considerable de materia orgánica humificada siendo esta condición característica de los suelos de climas fríos.

\section{Aislamiento y evaluación de las características microbiológicas}

En la Figura 1. se presentan los recuentos microbianos con su respectiva actividad metabólica.

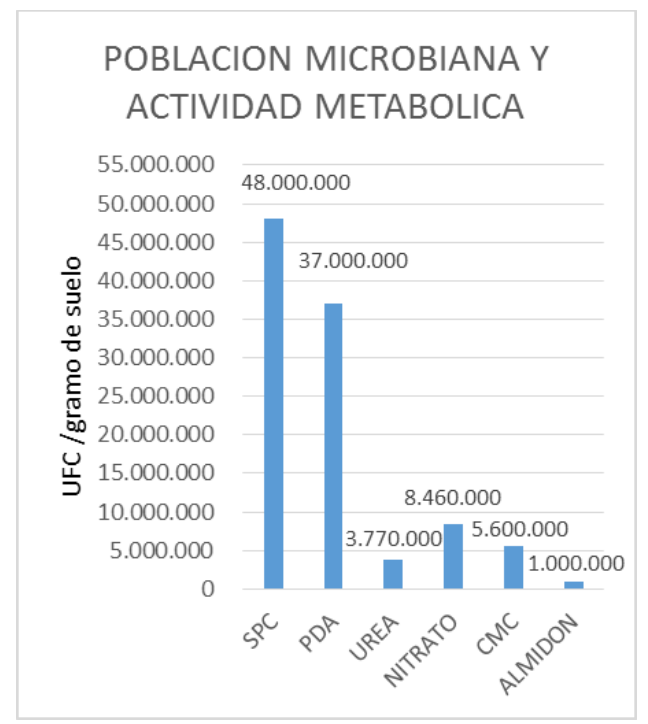

Figura. 1. Análisis de diferentes poblaciones microbianas y su respectiva actividad metabólica.

La población predominante fue la bacteriana, corroborando que son los microorganismos más abundantes pudiendo llegar incluso hasta cien millones por gramo de suelo. Dentro de la evaluación microbiológica se estableció que por la actividad metabólica de las diferentes poblaciones de microorganismos hay mayor participación en el ciclo del nitrógeno siendo de un $28.7 \%$ y se 
09

señala una baja participación en cuanto al ciclo del carbono, siendo del 15.5\%. Estos comportamientos están influenciados por la participación humana proporcionando fuentes de nitrógeno por variación de cultivos y adición de abonos nitrogenados y también por el retiro de desechos vegetales sesgando el desarrollo de algunos microorganismos y brindando los sustratos necesarios para favorecer el desarrollo de otros.

Los microorganismos nitrificantes de las muestras del suelo, presentaron una alta proporción, representando la población más grande obtenida en relación a las demás y comparando con el estudio realizado por Botello \& col., (2014) quienes de igual manera, emplearon la técnica de micro diluciones.

La población de bacterias amonificantes determinadas en este estudio estuvo una unidad logarítmica por debajo del total, similar a lo reportado por Pozuelo, (1991) quien encontró en la rizosfera de los árboles de la especie Alnus glutinosa aproximadamente 67 millones de bacterias por gramo de suelo. Esto es debido a la relación entre la actividad enzimática de la ureasa (amonificantes) con la temperatura y la cantidad de materia orgánica; a una temperatura del suelo que oscila entre los $18^{\circ} \mathrm{C}$ se dificulta la capacidad de desarrollo de los microorganismos que hidrolizan la urea y por ello la población presente en este suelo no es muy abundante, como lo demostró Núñez \& col., (2012).

En el presente estudio se encontraron concentraciones de $5 \times 10^{6}$ UFC /gr de suelo de microorganismos celulíticos y $1 \times 10^{6} \quad$ UFC/gr de suelo de microorganismos amilolíticos, desde esta perspectiva la biota presente es adecuada, y se puede deducir que ella aumentaría a medida que se ingresen sustratos vegetales y abonos orgánicos.

En el estudio realizado por Pérez., (2008) se encontraron entre $3.7 \times 10^{5} y$ $5.5 \times 10^{4}$ UFC caracterizados por la acción de la exoenzima celulasa y $5.1 \times 10^{5}$ y $5.3 \times 10^{4}$ UFC con actividad amilasa en suelos sin intervenir en los municipios de Girón y Piedecuesta en Colombia, evidenciando que la actividad humana en la agricultura influye sobre la densidad de las poblaciones microbianas y corroborando la veracidad de los métodos empleados siendo los mismos del presente estudio.

Buitrago \& col., (2014) obtuvieron a partir de una muestra de suelo, 19 cepas diferentes por el método de hidrólisis en agar almidón, presentando halos de hidrólisis entre 7 y $14 \mathrm{~mm}$ de diámetro acorde a los resultados obtenidos ya que los halos están entre 8 y $10 \mathrm{~mm}$ de diámetro 
Microorganismos antagonistas

Los microorganismos antagonistas juegan un papel muy importante a la hora de controlar poblaciones en el suelo. Se lograron aislar 10 morfoespecies diferentes (Tabla 4), que fueron identificadas mediante las claves taxonómicas de Rojas Flores \& Teresa., (1997) y Carrillo, (2003).

Tabla 4. Hongos aislados a partir del suelo.

\begin{tabular}{|c|c|}
\hline Morfo-especie & Género \\
\hline 1 & Curvularia spp. \\
\hline 2 & Colletotrichum $\mathrm{spp}$. \\
\hline 3 & Penicillium $\mathrm{spp}$. \\
\hline 4 & Fusarium $\mathrm{spp}$. \\
\hline 5 & Cunningamella $\mathrm{spp}$. \\
\hline 6 & Fusarium $\mathrm{spp}$. \\
\hline 7 & Aureobasidium $\mathrm{spp}$. \\
\hline 8 & Cunningamella $\mathrm{spp}$. \\
\hline 9 & Botrytis $\mathrm{spp}$. \\
\hline 10 & Paecilomyces $\mathrm{spp}$. \\
\hline
\end{tabular}

El hongo identificado como Penicillium spp. presentó un poder antagónico contra Escherichia coli y Staphylococcus aureus. En hongos de este género los principales antibióticos que se producen son los tipo B lactámicos donde, es incompleto el conocimiento del modo de acción, pero el fenómeno básico consiste en el deterioro de la pared celular del microorganismo (Valsecia, 2012). Lo normal en cepas de Escherichia coli es que no exista una resistencia intrínseca a ß-lactámicos según la CLSI, 2010, aunque puede ser adquirida mediante material genético extracelular como los plásmidos (Sánchez \& col., 2003).
10

La cepa evaluada de $S$. aureus también resultó ser inhibida por este hongo. Por lo general, los estafilococos presentan resistencia a la penicilina por lo que la prevalencia de $S$. aureus susceptible a penicilina es baja. En 1984, Mc Douglas y Thornsberry describieron por primera vez la aparición de cepas de $S$. aureus con susceptibilidad intermedia a las penicilinas, y definieron el concepto de $S$. aureus con susceptibilidad "borderline". En estudios realizados en Perú por Mendoza \& col., (2003), de las 76 cepas de $S$. aureus aisladas, 15 tuvieron susceptibilidad "borderline".

\section{Conclusiones}

El suelo al presentar un $\mathrm{pH}$ de 5,5 y ser ligeramente ácido brinda condiciones óptimas para que la mayoría de microorganismos presentes en él, se puedan desarrollar siendo en conjunto con la porosidad, humedad y capacidad de retención de agua parámetros óptimos los cuales permiten solubilizar muchos nutrientes para que puedan ser aprovechados y por las características de la textura no permite la lixiviación, lo que condiciona un nicho ecológico óptimo rico en sustratos orgánicos.

Aproximadamente un $55.8 \%$ de los microorganismos no intervienen dentro del ciclo del nitrógeno (amonificantes, nitrificantes, 
11

denitrificantes) ni dentro del ciclo de carbono (celulolíticos y amilolíticos) por lo que se propone estudiar otras actividades que puedan llevar a cabo como solubilización de hierro, degradación de la lignina, solubilizadores de azufre etc., para así estimar el comportamiento de la mayoría de los microorganismos.

La mayor actividad presente en el medio fue de microorganismos nitrificantes siendo esta de un $17.87 \%$ con respecto a la media estimada siendo esta de 42'500.000 millones de UFC por gramo (100\%).

Los microorganismos con actividad amilolítica están presentes en menor proporción siendo de un $2,35 \%$ en relación al total de la densidad poblacional.

De los 10 microorganismos seleccionados como productores de antibióticos sólo 1 clasificado taxonómicamente como Penicillium spp., tuvo actividad inhibidora contra E. coliy S. aureus.

\section{Referencias Bibliográficas}

Cruz-Núñez, O., (2013). El cultivo del maíz, manual para el cultivo de maíz en honduras. Secretaría de agricultura y ganadería dirección de ciencia y tecnología agropecuaria.

http://www.dicta.hn/files/Manualcultivo-de-MAIZ--III-EDICION,-2013.pdf
Lacasta, C., Benitez, M., Maire, N., Meco, R., (2006). Efecto de la textura del suelo sobre diferentes parámetros bioquímicos. VII CONGRESO SEAE ZARAGOZA $\mathrm{N}^{\circ} 110$. Http://digital.csic.es/bitstream/102 61/16622/1/2006\%20Biosuelos.pdf

Mendoza-Ticona, C, A., VelasquezTalavera, R., Mercado-Diaz, L., Ballon-Echegaray, J., MaguiñaVargas, C. (2003). Susceptibilidad antimicrobiana de Staphylococcus aureus sensible, con sensibilidad "BORDERLINE" y resistentes a la meticilina. Revista Médica Herediana, 14(4), 181-185. http://www.scielo.org.pe/scielo.ph p?script=sci arttext\&pid=S1018130X2003000400006

Parra R.A.L, ROC Villanueva (2013).Bioremediacion de aguas con fosfatos y nitratos utilizando Scenedesmus incrasssatulus inmovilizado.Revista Bistua.10(1): 71-79

Rodríguez L, V. (2002).Efecto antagonico y biocontrolador de algunos microorganismos saprofiticos contra Rhizoctonia solani un fitopatogeno causante del (damping off) en plantad de tomate.. (Tesis de pregrado). Facultad de farmacia y bioquímica. Universidad mayor nacional de San Marcos. http://sisbib.unmsm.edu.pe/bibvirt 
12

ualdata/Tesis/Salud/Rodriguez_LV/T_co mpleto.PDF

Salamanca-Jiménez, A., SadeghianKhalajabadi, S., (2005) La densidad aparente y su relación con otras propiedades en suelos de la zona cafetera colombiana, Cenicafé, 56(4):381-397.

https://www.cenicafe.org/es/publicati ons/arc056(04)381-397.pdf

Sánchez-Merino, J.M., Guillán-Maquieira, C., Fuster-Foz, C., Madrid-García, F.J., Jiménez-Rodríguez, M., GarcíaAlonso, J., (2003). Sensibilidad microbiana de Escherichia coli en infecciones urinarias extrahospitalarias. Actas Urol Esp. 27 (10): 783-787. http://scielo.isciii.es/pdf/aue/v27n10/ 783-787.pdf

A.M. Cajiao Pedraza Universidad de Pamplona, Maestría en Biología Molecular y Biotecnologia (sin Graduación) Universidad de Pamplona. Docente Tiempo Completo Ocasional, Departamento de Microbiología, Facultad de Ciencias Básicas, Universidad de Pamplona; integrante del Grupo de Investigación en Microbiología y Biotecnología -GIMBIO-. https://orcid.org/0000-0002$\underline{8090-8566}$

O.L. Rojas Contreras, Microbióloga Universidad de Pamplona, Especialista en Química Ambiental - Universidad Industrial de Santander - UIS (2001), Magister en Ciencia y Tecnología de Alimentos.Universidad de Pamplona. Docente Tiempo Completo Ocasional, Departamento de Microbiología, Facultad de Ciencias Básicas, Universidad de Pamplona; integrante del Grupo de Investigación en Microbiología y Biotecnología -GIMBIOhttps://orcid.org/0000-00019184-9031.

K.J Rivera Villamizar.Microbiologo. Universidad de Pamplona. Integrante del Grupo de Investigación en Microbiología y Biotecnología -GIMBIO-. https://orcid.org/0000-00034667-4142

*Para citar este artículo: Rojas C. L.; Cajiao P. A.; Rivera V. K.Study and presumptive characterization of soil from a corn crop (Zea mays) in Pamplona, Norte de Santander.Revista Bistua.2018.16(1):03-12

+ Autor para el envió de correspondencia y la solicitud de las separatas: Rojas C.L.Universidad de Pamplona, Facultad de Ciencias Básicas, Departamento de Microbiologia.email: olrojas@unipamplona.edu.co

Recibido: Octubre 18 de 2016 Aceptado: Noviembre 15 de 2017 